\title{
Application of Multi-Agent Technology in Micro-Grid System
}

\author{
Xingbei Jia and Chunxia Dou \\ Institute of Electrical Engineering, Yanshan University, Qinhuangdao City \\ 066004, China \\ Jiaxingbei1986@163.com
}

\begin{abstract}
This paper proposes a multi-agent technology to energy management of the distributed generations in a micro-grid (MG) system. An introduction and analysis of the distributed intelligent multi-agent technology are presented, including its architecture and operation mechanism. Then, the objective function about minimizing the operating cost and environment losses taking in electricity trading is given. An implementation of Central Force Optimization (CFO) utilizing variable initial probes and decision space adaptation is presented, and Compare it to particle swarm optimization (PSO) method. The daily load forecast of electric power system is presented. The simulation results demonstrate that the proposed multi-agent technology is successfully monitored, controlled and operated for the energy management of the distributed generations in micro-grid system.
\end{abstract}

Keywords: micro-grid system; multi-agent; objective function; electricity trading; load forecast

\section{Introduction}

Power generation has seen an increased penetration of distributed generation(DG) in recent times. The drive of distributed generation development is the needs for more flexible electric systems, investment minimizing, energy savings and environmental impact. The following goals should mainly be achieve:

- Cost reduction for investor:

- Integration and promotion of renewable resources;

- Reduction of the environmental impact due to load growth;

- Stable operation of the system and load satisfaction.

Pursuit of these goals promoted the creation of "MG" [1]. MG usually have been described as confined clusters of loads, storage devices and small micro sources $(\leq 500 \mathrm{KW})$, these autonomous networks connect as single entities to the public distribution grid[2]. With gradually deepening the study on MG, it plays an increasing role in future power systems.

MG has some mainly characteristics[3]: the first, it includes distributed generation such as wind turbine(WT), PV arrays(PV), micro-turbine(MT), full cell(FC), etc.; the second, it has Energy Management System(EMS) for solving problems about power flow and network protection etc.; the last, MG can be run with large power system, and also can be run alone with effectively controlling all distributed generations when large power system is out of order.

From the above characteristics can clear that MG system is flexible and has a large number of control data, so if the MG system adopt the traditional centralized control approach, it is difficult to meet demands about effectively and flexible. Therefore, this paper proposes a multi-agent system (MAS) technology to energy management of the distributed generations in a MG system.

The MAS have demonstrated their potential for solving complex problems in various domains [4]. The attribute of agents, which lends itself to problem solving, is intelligence, 
which refers to the level of reasoning and learned behavior exhibited by an agent [5]. Therefore, some researches about application of Multi-agent technology to energy management in energy generation system can be seen in some literature, such as [6-8]. In addition, many significant researches have been conducted in optimization objective function of application of multi-agent technology in micro-grid system, which have many different aspects. In the literature [9], it aims to maximize the output of wind turbine and $\mathrm{PV}$ arrays for best use of economic resources. The profit-maximizing object of MG based on the proposed bidding system is given in $[10,11]$. The optimization and maximization of the system's benefits must be taken into account with a system view can be seen in [6]. In [12], the active power loss has been adopted as optimized aim. In addition, many researches have been conducted in Bidding Strategies for MG [13-16]. Thus in this paper, aims to minimize MG's cost while constraining it by an Optimization Bidding Strategies are given.

The contributions of this paper are summarized as several points as follows. First, the statuses of the application of Multi-agent technology in micro-grid system are introduced. Profoundly study the multi-agent technology about its constituents, and operation mechanism; second, the bidding function and objective function about micro-grid system are given. Third, Central Force Optimization (CFO) is new optimization metheuristic for optimize are provided; the last, load derivation algorithm has been proposed for shorttime load forecasting.

\section{Multi-Agent System (MAS)}

The original meaning of agent is proxy, that one person represents another person or an organization to complete something. In the field of computer, agent can be seen as "personal assistant software", the Software can play their effect sostenuto and independently in a distributed system or the cooperation system. Agent has some properties such as action on behalf others, autonomy, initiative, reactiveness, interaction, intelligence, mobility etc.

MAS is a loosely and coupled network structure and constituted by some agents. The agents is dispersive in physics or logic; its behavior is autonomous; it get together in order to complete a task or to achieve some purpose and links up through abide by some kind of agreement; it solve the problems about skills and knowledge beyond a single agent's ability through the exchange and cooperation.

Multi-agent technology is a branch of distributed artificial intelligence; it has very good adaptability and coordination ability and can make the logic or physical dispersive system problems to solve with coordination. The characteristics of power system are regional spread wide, low efficiency and data redundancy, so, multi-agent technology can well solve reactive power optimization of power system.

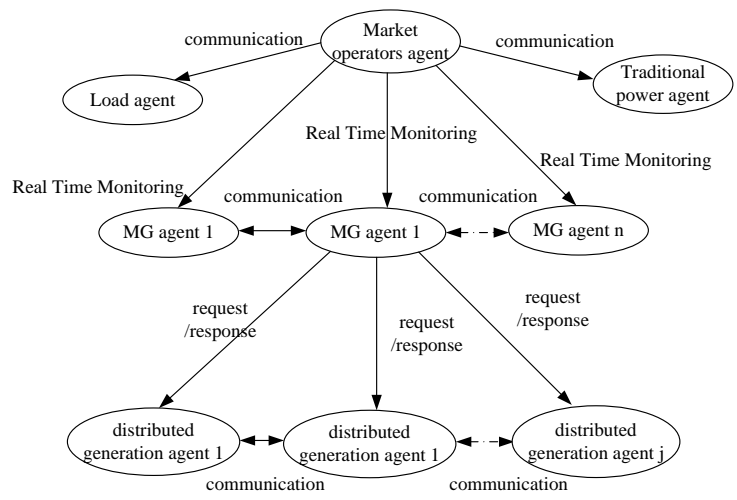

Figure 1. Implemented Coordination between Agents 
In this paper, the multi-agent technology to energy management of the distributed generations in a micro-grid system is shown in Figure.1. The agents are including market operator's agents, traditional power agents, MG management agents, distributed generation agents and load agents respectively. The market operator's agents with the responsibility for classifying the types of lower agents, deciding on the trading plan for the real-time market. The main task of The MG Management Agent is that control and management of the MG, and simultaneously monitoring DG units. The load agents send the information to market operator's agent when monitoring internal load. Distributed generation agents adjust the capacity of output power from distributed units.

The main task of MAS is on behalf of the whole MG to interact with the main power grid, to seek the best interest of the whole operation. It can take advantage of the information of MG electricity market price for providing a purchasing power planning; In addition, it can take advantage of the information of load and distributed power supply Output for bidding power in electric power market and Optimization of distributed power supply output. According to the proposed main task of MAS, each agent has the autonomy to execute its behavior in parallel or concurrently with the others. Generic structure of such an intelligent agent is shown in Figure 2.

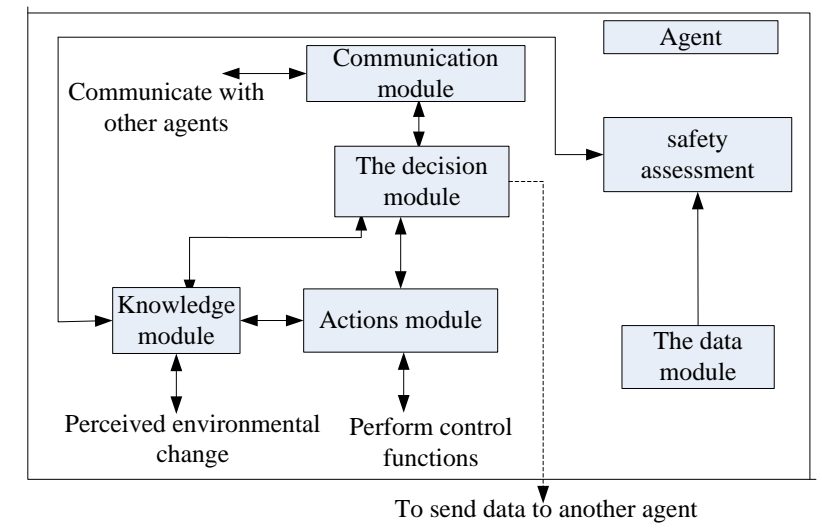

Figure 2. The Multi-Agent Distributed Control Structure

\section{Proposed Bidding Function and Objective Function}

According to the characteristics of the $\mathrm{MG}$, is proposed an electricity market model of MAS. At the same time, considering the micro grid Special properties, respectively from the optimal bidding strategy and internal power management is studied, it is concluded that the MG profit maximization of the race Price strategy and operation plan. These two aspects can be proposed in the following.

\subsection{Bidding Function}

Assumptions: there are N MGs for electricity market sell electricity, one of them as the breakthrough point can be researche, and the cost function is following:

$$
W\left(P_{G}(t)\right)_{i}=a_{i}\left(P_{G}(t)\right)^{2}+b_{i} P_{G}(t)+c_{i}
$$

Where $i=1,2, \cdots, N-1 ; W_{i}$ is the cost function; $a_{i}, b_{i}, c_{i}$ are coefficients of the quadratic curve for the cost; $a_{i}\left(P_{G}(t)\right)^{2}+b_{i} P_{G}(t)$ is Variable costs including fuel costs, electricity purchase cost, consumption of materials cost and discharge pollution gas cost ; $c_{i}$ is fixed cost , that is the micro power supply start-up costs.

Considering the uncertainty of the market, as a self-sustaining sell electricity Enterprise, 
the MG in order to optimize its profits, usually in the bidding on the basis of the cost function with certain proportion factor $\lambda_{i}$, the cost function of the MG can be obtained as:

$$
W\left(P_{G}(t)\right)_{i}=\left(1+\lambda_{i}\right)\left(a_{i}\left(P_{G}(t)\right)^{2}+b_{i} P_{G}(t)+c_{i}\right)
$$

Equation of profits maximized for the ist $\mathrm{MG}$ at time $t$ can be obtained as:

$$
\pi_{i}=m P_{G}(t)-W_{i}
$$

where $\pi_{i}$ is the target profit of ist MG, $P_{G}(t)$ is the output power of ist MG at time $t$, $m$ is the electricity price at the moment.

Because other MG power generation cost is unknown variables, only get their probability Distribution. Hypothesis, the probability distribution is shown in table 1 .

\section{Table 1. The ist MG's Probability Distribution of Cost of Production and} Fluctuation Factor

\begin{tabular}{rccccc}
\hline$W_{i}$ & $W_{i}^{(1)}$ & $\ldots$ & $W_{i}^{(l)}$ & $\ldots$ & $W_{i}^{\left(m_{i}\right)}$ \\
\hline $\begin{array}{c}\text { prob } \\
\text { ability }\end{array}$ & $\mu_{i}^{(1)}$ & $\ldots$ & $\mu_{i}^{(l)}$ & $\ldots$ & $\mu_{i}^{\left(m_{i}\right)}$ \\
$\lambda_{i}$ & $\lambda_{i}^{(1)}$ & $\ldots$ & $\lambda_{i}^{(k)}$ & $\ldots$ & $\lambda_{i}^{\left(M_{i}\right)}$ \\
$\begin{array}{c}\text { prob } \\
\text { ability }\end{array}$ & $\eta_{i}^{(1)}$ & $\ldots$ & $\eta_{i}^{(k)}$ & $\ldots$ & $\eta_{i}^{\left(M_{i}\right)}$ \\
\hline
\end{tabular}

When the ist MG's probability distribution is $W_{i}^{(l)}$ and fluctuation factor is $\lambda_{i}^{(k)}$, the probability of the cost function can be obtained as:

$$
\mu\left(W_{i}=W_{i}^{(l)}, \lambda_{i}=\lambda_{i}^{(k)}\right)=\mu_{i}^{(l)} \eta_{i}^{(k)}
$$

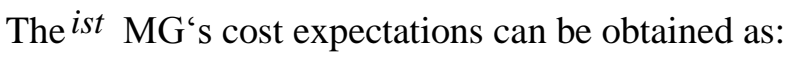

$$
E\left(W_{i}\right)=\sum_{l=1}^{m_{i}} \sum_{k=1}^{M_{i}} \mu_{i}^{(l)} \eta_{i}^{(k)}\left(1+\lambda_{i}^{(k)}\right) W_{i}^{(l)}
$$

Cost expectations have floating factor $\bar{\lambda}_{i}$. The cost function of the MG can be obtained as:

$$
\overline{W\left(P_{G_{i}}(t)\right)_{i}}=\left(1+\overline{\lambda_{i}}\right)\left(\overline{a_{i}}\left(P_{G_{i}}(t)\right)^{2}+\bar{b}_{i} P_{G_{i}}(t)+\overline{c_{i}}\right)
$$

Equation of profits maximized for the ${ }^{i s t} \mathrm{MG}$ at time ${ }^{t}$ can be obtained as:

$$
\begin{aligned}
& \overline{\pi_{i}}=m P_{G_{i}}(t)-\overline{W_{i}} \\
& =m P_{G_{i}}(t)-\left(1+\overline{\lambda_{i}}\right)\left(\overline{a_{i}}\left(P_{G_{i}}(t)\right)^{2}+\bar{b}_{i} P_{G_{i}}(t)+\overline{c_{i}}\right)
\end{aligned}
$$

According to the equilibrium condition can get the following formula:

$$
\frac{\partial \pi_{i}}{\partial P_{G}(t)}=\frac{\partial \bar{\pi}_{i}}{\partial P_{G_{i}}(t)}=0
$$

The power total output of micro grid can be obtained as:

$$
P=P_{G}+\sum_{i=1}^{N-1} P_{G_{i}}+P_{b u y}
$$


By solving simultaneous equation of (1) to (9), the optimal output of power for ${ }^{\text {ist }}$ MG after the bidding process can be obtained as:

$$
\overline{P_{G}(t)}=\frac{P+\sum_{i=1}^{N-1} \frac{\overline{b_{i}}}{2 \overline{a_{i}}}-\frac{\left(1+\lambda_{i}\right)}{\left(1+\overline{\lambda_{i}}\right)} \sum_{i=1}^{N-1} \frac{b_{i}}{2 \overline{a_{i}}}}{1+\frac{\left(1+\lambda_{i}\right)}{\left(1+\overline{\lambda_{i}}\right)} \sum_{i=1}^{N-1} \frac{b_{i}}{a_{i}}}
$$

Where $N$ is the number of all the players in the competition, and $P$ is the total load demands given by the system center at time $t$, the expected price also can be obtained as:

$$
\overline{m_{i}\left(P_{G_{i}}(t)\right)}=\frac{\partial W_{i}}{\partial P_{G_{i}}}=\left(1+\bar{\lambda}_{i}\right)\left(2 \bar{a}_{i} P_{G_{i}}(t)+\bar{b}_{i}\right)
$$

Where $\overline{m_{i}\left(P_{G_{i}}(t)\right)}$ is the expected price for ist MG, and after those prices of all the generation companies are ranked, the highest bid is set as the cleaning price of the MGcontained market.

\subsection{Objective Function}

The aim of objective function for optimal generator output planning used in this paper based on the maximum profit considering the costs of operation, maintenance and fuel emission of atmospheric pollutants and buying (selling) electricity. The maximum profit objective function can be expressed as:

$$
\begin{gathered}
\min F=C_{o s t}\left(p_{i j}\right)+s_{p c c} Q\left(p_{i j}\right) \\
Q\left(p_{b s}\right)=p_{\text {sell }} * m_{\text {sell }}-p_{\text {buy }} * m_{\text {buy }} \\
C_{\text {ost }}\left(p_{i j}\right)=\left[\xi_{1} f_{1}\left(p_{i j}\right)+\xi_{2} f_{2}\left(p_{i j}\right)\right]
\end{gathered}
$$

$F$ is the consume of power generation. $Q\left(p_{i j}\right)$ is the value about selling(buying) electricity to large power system. $C_{o s t}\left(p_{i j}\right)$ is the total power production costs. $f_{1}$ is the maintenance, consume and fuel costs of distributed generation. $F_{2}$ is the amount of gas pollution punishment. $\xi_{1}$ And $\xi_{2}$ are weight coefficients of multiple objective function, and content $\xi_{1}+\xi_{2}=1$.

$$
\begin{gathered}
f_{1}=\sum_{i=1}^{m} \sum_{j=1}^{n} s_{i j}\left[p_{i j}\left(\alpha_{i j}+\beta_{i j} * \chi_{i j}\right)+s t_{i}\right] \\
f_{2}=\sum_{l=1}^{q} \sum_{i=1}^{R} \sum_{j=1}^{M} s_{i j}\left(p_{i j} * e_{i l}+p_{i j}^{2} * h_{i l}\right) * v_{l}
\end{gathered}
$$

Where, $R$ is the number of the types of distributed generations, $M$ is the number of the distributed generations of the ist type, $m_{b u y}$ and $m_{\text {sell }}$ are the electricity prices, $s_{i j}$ is the commitment status of the $j s t$ distributed generation of the ist type and $s_{i j} \in[0 ; 1], p_{i j}$ is Active power output of the ist distributed generation of the ist type in $k w, \beta_{i j}$ is the fuel costs of the ist type of distributed generation in $\$ / \mathrm{kg}, \chi_{i j}$ is the fuel consumption rate of the ist type of distributed generation in $k g /(h * k w), \alpha_{i j}$ is the operation and maintenance costs proportional constant of the ist type of distributed generation in $\$ /(h * k w)$, st $t_{i}$ is the 
start up costs of the ist type distributed generation, $q$ is the number of the types of atmospheric pollutants, $e_{i l}$ and $h_{i l}$ is emission rate coefficient of the lst type of atmospheric pollutant in $\mathrm{km}^{3} / \mathrm{kw}, V_{l}$ is amercement of the lst type of atmospheric pollutant emission in $\$ / \mathrm{km}^{3}$.

\subsection{Objective Function's Constraints}

Power balance constraint: To meet the active power balance, an equality constraint can be written as

$$
\sum_{i=1}^{N} \sum_{j=i}^{M} s_{i j} p_{i j}+p_{\text {buy }}-p_{\text {sell }}-p_{\text {Load }}=0
$$

WT and PV may experience large variations of its output power under variable weather conditions, which may result in control problems, so see its output power as load. The above formula (4) has been rewritten as follows

$$
\xi_{i} \sum_{i=1}^{N} \sum_{j=i}^{M} s_{i j} p_{i j}{ }^{\prime}+p_{\text {buy }}-p_{\text {sell }}-\left(p_{\text {Load }}+p_{W T}+p_{P V}\right)=0
$$

Where, $p_{i j}{ }^{\prime}$ is active power output of the $j s t$ distributed generation of the ist type except output power of WT and PV in $k w, p_{W T}$ is active power output of WT, $p_{P V}$ is active power output of PV and $p_{\text {Load }}$ is the total power demand.

Grid interconnection capacity constraint:

$$
\begin{aligned}
& p_{p c \text { min }} \leq p_{b u y} \leq p_{p c c \text { max }} \\
& p_{p c \text { min }} \leq p_{\text {sell }} \leq p_{p c c \text { max }}
\end{aligned}
$$

Where, $p_{p c c \text { min }}$ is the minimum power that can be transferred from the MG at the PCC, $p_{p c \text { max }}$ is the maximum power that can be transferred from the MG at the PCC.

Generation capacity constraint: For stable operation, real power output of each distributed generation is restricted by lower and upper limits as follows

$$
p_{i}^{\min }<p_{i}<p_{i}^{\max } \quad i=1, \ldots \ldots, N
$$

Where, $p_{i}^{\min }$ is minimum operation power of the ist type of distributed generation in $k w, p_{i}^{\max }$ is maximum operation power of the ist type of distributed generation in $k w$.

\subsection{Constrained Objective Function Is Converted}

The objective constraints of formulation have been confirmed. Penalty function methods are used for solving constrained optimization problems. A penalty function method can convert a constrained optimization problem into an unconstrained problem. The unconstrained problems are formed by adding a term to the objective function that consists of a penalty parameter and a measure of violation of the constraints. The measure of violation is nonzero when the constraints are violated.

In this paper, non-stationary multi-stage assignment penalty function is adopted for solving optimization problem; it can significantly improve the convergence and gain more accurate values. The penalty values are dynamically modified according to equality constraints and inequality constraints $[17,18]$.

The new objective function can be expressed as

$$
\begin{aligned}
& \min F=\left[\xi_{1} f_{1}\left(p_{i j}\right)+\xi_{2} f_{2}\left(p_{i j}\right)\right] \\
& -Q\left(p_{i j}\right)+\sigma(k) H\left(p_{i j}\right)
\end{aligned}
$$




$$
\begin{gathered}
H\left(p_{i j}\right)=\sum_{t=1}^{m} \theta\left(q_{t}\left(p_{i j}\right)\right) q_{t}\left(p_{i j}\right)^{r\left(q_{t}\left(p_{i j}\right)\right)} \\
q_{t}\left(p_{i j}\right)=\max \left\{0, g_{t}\left(p_{i j}\right)\right\} \\
r\left(q_{t}\left(p_{i j}\right)\right)= \begin{cases}1, & q_{t}\left(p_{i j}\right)<1 \\
2, & q_{t}\left(p_{i j}\right)>1\end{cases} \\
\theta\left(q_{t}\left(p_{i j}\right)\right)=\left\{\begin{array}{lc}
5, & q_{t}\left(p_{i j}\right)<0.001 \\
10, & q_{t}\left(p_{i j}\right) \leq 0.1 \\
15, & q_{t}\left(p_{i j}\right) \leq 1 \\
30, & \text { others }
\end{array}\right.
\end{gathered}
$$

Where $\sigma(k)$ is a dynamically modified value, $k$ is the algorithm's current iteration number. In general, $\sigma(k)=k \sqrt{k} ; H\left(p_{i j}\right)$ is penalty factor, defined as equation(10). $m, n$ are the number of equality constraints and inequality constraints respectively. The function $q_{t}\left(p_{i j}\right)$ is a relative violated function of the constraints; $\theta\left(q_{t}\left(p_{i j}\right)\right)$ is a multistage assignment function ; $r\left(q_{t}\left(p_{i j}\right)\right)$ is the power of the penalty function.

Dualistic factor contrast for indexes weight calculation based on fuzzy mathematics is established in a practical and effective Method to determine the weight $\xi_{i}$. The steps of

\begin{tabular}{|c|c|c|c|c|c|}
\hline $\begin{array}{c}\text { mo } \\
\text { od } \\
\text { operato }\end{array}$ & $\begin{array}{l}\text { fuzz } \\
\text { y scale }\end{array}$ & $\begin{array}{l}\text { me } \\
\text { mbersh } \\
\text { ip }\end{array}$ & $\begin{array}{c}\text { mo } \\
\text { od } \\
\text { operato }\end{array}$ & $\begin{array}{l}\text { fuzz } \\
\text { y scale }\end{array}$ & $\begin{array}{l}\text { me } \\
\text { mbersh } \\
\text { ip }\end{array}$ \\
\hline $\mathrm{r}$ & & degree & $\mathrm{r}$ & & degree \\
\hline \multirow{4}{*}{$\begin{array}{l}\text { Equ } \\
\text { al }\end{array}$} & 0.50 & 1.0 & \multirow{4}{*}{$\begin{array}{r}\mathrm{Re} \\
\text { markab } \\
\text { ly }\end{array}$} & 0.8 & 0.2 \\
\hline & 0 & 00 & & 00 & 05 \\
\hline & 0.52 & 0.9 & & 0.8 & 0.2 \\
\hline & 5 & 05 & & 25 & 12 \\
\hline \multirow{4}{*}{$\begin{array}{l}\text { Slig } \\
\text { htly }\end{array}$} & 0.55 & 0.8 & \multirow{4}{*}{$\begin{array}{l}\text { Ver } \\
y\end{array}$} & 0.8 & 0.1 \\
\hline & 0 & 18 & & 50 & 76 \\
\hline & 0.57 & 0.7 & & 0.8 & 0.1 \\
\hline & 5 & 39 & & 75 & 43 \\
\hline \multirow{4}{*}{$\begin{array}{c}\text { So } \\
\text { mewha } \\
t\end{array}$} & 0.60 & 0.6 & \multirow{4}{*}{$\begin{array}{l}\text { Extr } \\
\text { a }\end{array}$} & 0.9 & 0.1 \\
\hline & 0 & 67 & & 00 & 11 \\
\hline & 0.62 & 0.6 & & 0.9 & 0.0 \\
\hline & 5 & 00 & & 25 & 81 \\
\hline \multirow{4}{*}{$\begin{array}{l}\text { Rat } \\
\text { her }\end{array}$} & 0.65 & 0.5 & \multirow{4}{*}{$\begin{array}{r}\text { Exc } \\
\text { eedingl } \\
y\end{array}$} & 0.9 & 0.0 \\
\hline & 0 & 38 & & 50 & 53 \\
\hline & 0.67 & 0.4 & & 0.9 & 0.0 \\
\hline & 5 & 81 & & 75 & 26 \\
\hline Obv & 0.70 & 0.4 & Extr & 1.0 & 0.0 \\
\hline iously & 0 & 29 & emely & 00 & 00 \\
\hline
\end{tabular}
this method are described as fellows.

\section{Table 2. Relationship of Mood Operator, Fuzzy Scale and Membership} Degree

1: Base on element set $D=\left\{d_{1}, d_{1}, \cdots, d_{n}\right\}$, make $d_{m}$ and $d_{l}$ contrast. $d_{i}$ is the ist element, $i=1,2, \cdots n$. If the $d_{m}$ is more important than $d_{l}$, then $e_{m l}=1, e_{l m}=0$. The opposite holds true. If $d_{m}$ and $d_{l}$ are equally important, then $e_{m l}=0.5, e_{l m}=0.5$. According to the table 2, every element is scored for determining the sort of the each two elements. Finally, the matrix $\boldsymbol{E}$ of which is the dualism compare sorting scale set will be got 


$$
E=\left[\begin{array}{cccc}
e_{11} & e_{12} & \cdots & e_{1 n} \\
e_{21} & e_{22} & \cdots & e_{2 n} \\
\cdots & \cdots & \cdots & \cdots \\
e_{n 1} & e_{n 2} & \cdots & e_{n n}
\end{array}\right]
$$

2: According to the relationship of fuzzy scale and membership degree in the table 1[19], weight vector $W^{\prime}$ which is non-normalized will be got.

3: Weight vector $W$ which make $W^{\prime}$ normalize will be got.

\section{Central Force Optimization}

Central Force Optimization (CFO) is new optimization metaheuristic that has been proposed and developed in recent years by Formato [20-21], and based on gravitational kinematics and a deterministic nature. In simple terms, the random initial several probes find optimal solutions by iteration. Each probe has a position vector, an acceleration vector, and a fitness value according to three basic equations: iteration:

$$
\begin{gathered}
a_{j-1}^{i}=G \sum_{k=1, k \neq p}^{N_{p}} U(F) * F^{\alpha} \frac{\left(R_{j-1}^{k}-R_{j-1}^{i}\right)}{\left|\left(R_{j-1}^{k}-R_{j-1}^{i}\right)\right|} \\
F=M_{j-1}^{k}-M_{j-1}^{i} \\
R_{j}^{i}=R_{j-1}^{i}+v_{j-1}^{i} \Delta t+\frac{1}{2} a_{j-1}^{i} \Delta t^{2} \\
U(F)=\left\{\begin{array}{l}
1, \\
0,
\end{array} \quad \begin{array}{c}
\text { otherwise } \\
0, R_{j-1}^{i}+\frac{1}{2} a_{j-1}^{i} \Delta t^{2} ;
\end{array}\right. \\
v_{j-1}^{i}=\frac{R_{j-1}^{i}-R_{j-2}^{i}}{\Delta t}
\end{gathered}
$$

Where $a_{j-1}^{i}$ is probe's acceleration at step $\mathrm{j}-1, R_{j}^{i}$ is position vector at step $\mathrm{j}, G$ is the gravitational constant, $N_{p}$ is the number of probes, $U$ is the unit step function, $\alpha$ and $\beta$ are constants that would be one and three in the real world. $M_{j-1}^{k}=f\left(x_{1}^{k, j-1}, x_{2}^{k, j-1}, \cdots, x_{N_{d}}^{k, j-1}\right)$ is the fitness of probe $k, \Delta t$ is the time interval between steps. The algorithmic framework of PSO is described as fellows.

1: Initialize a population of probe $p=\left\{x_{1}, x_{2}, \cdots, x_{N p}\right\}$, and then evaluate the objective values of all probes $f\left(x_{i}\right)$.

2: Evaluate its fitness values $f\left(x_{\text {best }}\right)$ according to compare with each probe's objective value, and then determine the best probe $x_{\text {best }}$.

3: Evaluate the acceleration vector of each probe according to (23) and (24).

4: Update the objective value of each probe according to (25).

5: After Updating, if meet the terminal condition, then stop and output the solution. If not, go to Step 3.

\section{Short-Term Load Forecasting Algorithm}

The daily load forecast of electric power system is an important routine for Power dispatch departments. In this paper, load derivation algorithm has been proposed for short-time load forecasting. 
Forecasting formula of load derivation algorithm is fowling as:

$$
p_{(i+1)}=p_{(i)}+\Delta p_{(i)}
$$

Where, $p_{i}(i=1,2, \cdots)$ is load sequence; $p_{(i+1)}$ is load forecasting value in the case of $i+1$ point; $\quad p_{(i)}$ is load actual value in the case of $i$ point; $\Delta p_{(i)}$ is predicted value of load change rate in the case of $i$ point to $i+1$ point.

Using average method, formula as shown in the following:

$$
\begin{gathered}
\Delta p_{(i)}=\frac{\sum_{k=1}^{n} p_{(i)}^{k^{\prime}}}{n}(k=1,2, \cdots, n) \\
p_{(i)}^{k^{\prime}}=\left(p_{(i+1)}-p_{(i)}\right) / p_{(i)}
\end{gathered}
$$

Where, $n$ is the number of samples. $p_{(i)}^{k^{\prime}}$ is sample's predicted value of load change rate in the case of $i$ point to $i+1$ point.

\section{Simulation}

\subsection{The Daily Load Forecast}

In this paper, the load real-time monitoring data of sampling is 4 days. Every day is divided into 24 points. Sampling curve as follows:
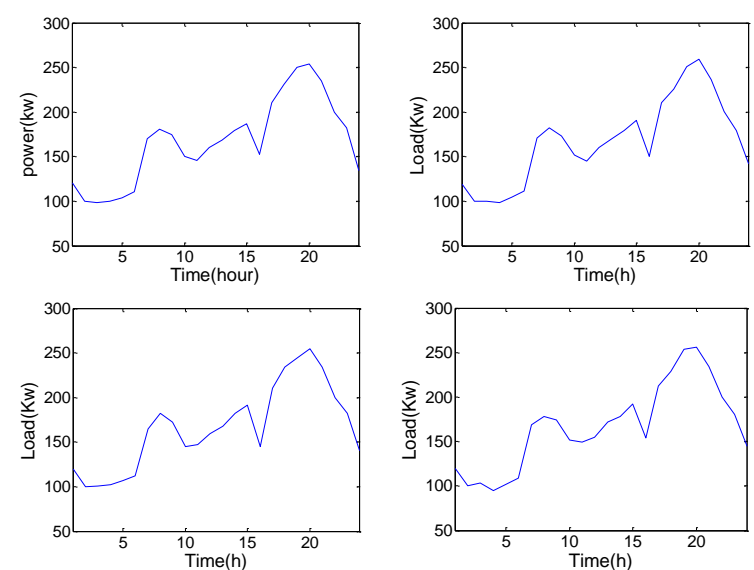

Figure 3. Four Days' Historical Load Demands Curves

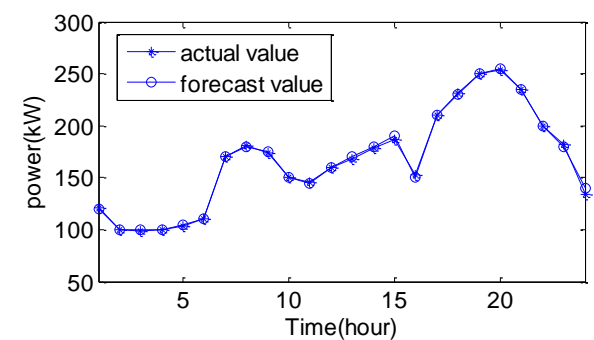

Figure 4. Daily Actual Value and Forecast Value Curves 
The curves of actual value and forecast value are given in the Figure 4. Based on the result of forecast can be shown that load derivation algorithm has the features $o$ f easy realization, quick operation and high precision.

WT and PV experience large variations under variable weather conditions, which may result in difference optimal result. The daily average output powers of WT and PV has been estimate showing in Figure5.

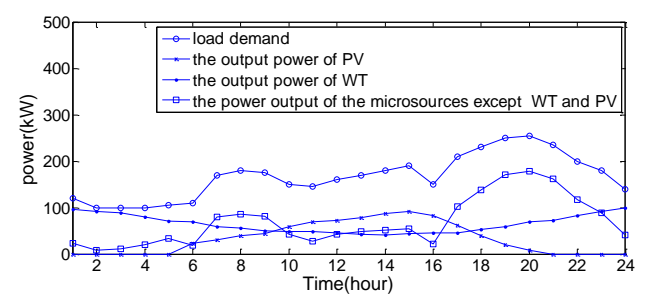

Figure 5. Daily Load Demands, Average Output Powers of WT And PV

Operation and maintenance costs proportional constant, unit capacity, minimum operation power, and maximum operation power of MT and FC can be seen in table 3.

Table 3. Data of MT and FC

\begin{tabular}{ccc}
\hline parameters & MT & FC \\
$\alpha_{i j}(\$ / k w)$ & 0.00589 & 0.00419 \\
$\chi_{i j}(\$ / k w)$ & 0.000032 & 0.000087
\end{tabular}

The proper order of magnitude of penalty for pollutant emission is a measure for environmental protection. The penalties of sulfur dioxide $\left(\mathrm{SO}_{2}\right)$, carbon oxides $\left(\mathrm{CO}_{2}\right)$, and nitrogen oxides $\left(N O_{x}\right)$ are $1 \$ / \mathrm{kg}, 0.01 \$ / \mathrm{kg}$ and $2 \$ / \mathrm{kg}$.

$\mathrm{PV}$ and WT are not release atmospheric pollutants. The atmospheric pollutants is split into two main release sources, sulfur dioxide $\left(\mathrm{SO}_{2}\right)$, carbon oxides $\left(\mathrm{Co}_{2}\right)$, and nitrogen oxides $\left(N O_{x}\right)$ are produced by $\mathrm{FC}$ and MT respectively. Characteristic of pollutant emission for different distributed generation has been proposed in table 4 .

Table 4. Characteristic of Pollutant Emission for MT and FC

\begin{tabular}{crrccc}
\hline $\begin{array}{c}\text { parame } \\
\text { ters }\end{array}$ & \multicolumn{1}{c}{$\mathrm{T}$} & \multicolumn{1}{c}{$\mathrm{C}$} & $\begin{array}{l}\text { parame } \\
\text { ters }\end{array}$ & \multicolumn{1}{c}{$\mathrm{T}$} & $\mathrm{FC}$ \\
\hline$e_{s o_{2}}$ & 0. & 0. & $h_{s o_{2}}$ & 0.0 & 0.00 \\
& 004 & 003 & & 59 & 28 \\
$e_{c o_{2}}$ & 3 & 5 & $h_{c o_{2}}$ & 364 & 89 \\
& 89.2 & 25.4 & & & 59.2 \\
$e_{N O_{x}}$ & 541 & 024 & $h_{N O_{x}}$ & 009 & 0.00 \\
\hline
\end{tabular}

\subsection{Simulation Results in Island}

In this part, $\mathrm{MG}$ is island, thus, Optimization Bidding Strategies does not considered. Daily output powers of FC and MT by CFO algorithm and PSO algorithm can be seen in Figure 6 and Figure 7. From the Figure 6 and Figure 7 we can clearly see that the output powers of FC and MT with some slight and subtle differences in CFO and PSO. This means that load demands are satisfied by PV, WT, FC and MT with optimum power allocation.

Objective function value is the investment funds. The curves of Figure 8 can be seen Daily function values by CFO algorithm and PSO algorithm. In Figure 8, the function values by $\mathrm{CFO}$ algorithm are lower than the function values by PSO 
algorithm. The results demonstrate the validity and high efficiency of the proposed $\mathrm{CFO}$ algorithm and CFO algorithm is more accurate compared with PSO algorithm.

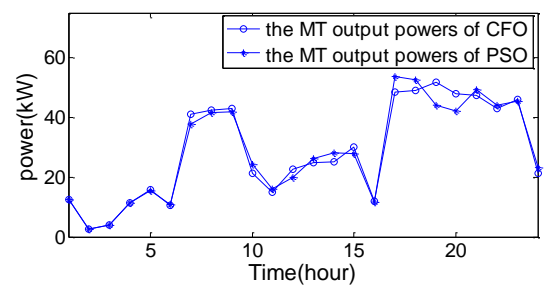

Figure 6. Daily MT Output Powers by CFO Algorithm and PSO Algorithm

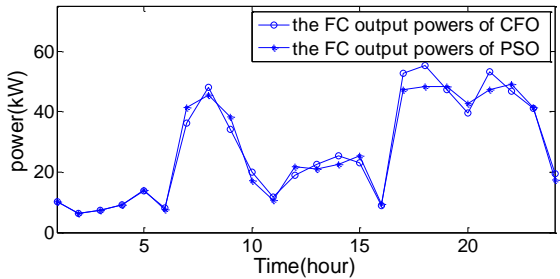

Figure 7. Daily FC Output Powers by CFO Algorithm and PSO Algorithm

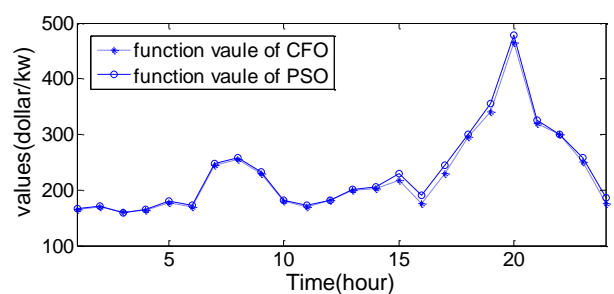

Figure 8. Daily Function Values

\subsection{Simulation Results in Connect Power Grid}

This paper adopts a bidding system model three MGs companies, which are competing with each other for the bidding power from market operator's agents. In This paper, MG1 as a breakthrough point.

The value of proportion factor $1+\lambda$ can be evaluation as $0.8,1$ and 1.2 ; the probability distribution can be shown in table 5. The cost function of three MGs can be obtained by historical data.

Table 5. The Probability Distribution of Proportion Factor

\begin{tabular}{ccc}
\hline proportion factor & MG 2 & MG 3 \\
\hline 1.2 & 0.5 & 0.55 \\
1 & 0.4 & 0.25 \\
0.8 & 0.35 & 0.2
\end{tabular}

By solving the equations of (5)-(6), the Cost coefficients of can be obtained as in Table 6.

Table 6. Cost Coefficients for the MG2 And MG 3

\begin{tabular}{cccc}
\hline MG & $\overline{a_{i}}$ & $\overline{b_{i}}$ & $\overline{c_{i}}$ \\
\hline MG 2 & 0.194 & 20.060 & 45.139 \\
MG 3 & 0.137 & 27.816 & 32.597 \\
\hline
\end{tabular}


By solving the equations of (10)-(11), the bidding results can be obtained. Hence the optimization mode after the processing in this paper can be simulated as follows:

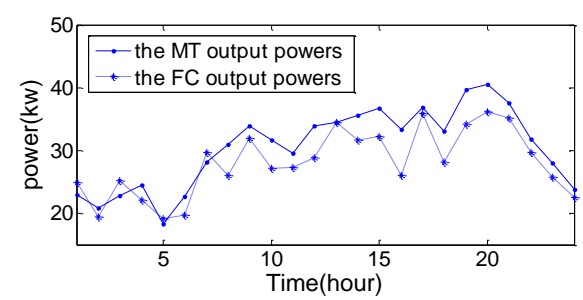

Figure 9. Daily MT and FC Output Powers by CFO Algorithm

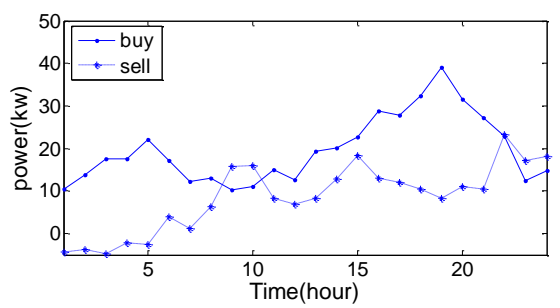

Figure 10. Daily Electricity Trading Powers

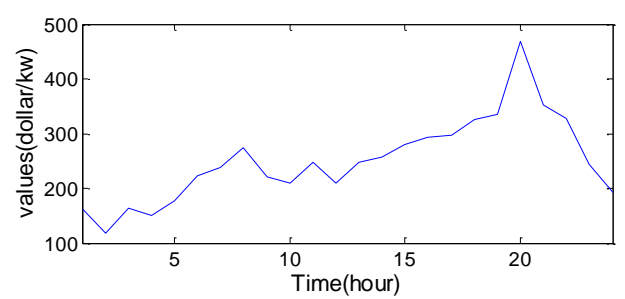

Figure 11. Daily Function Values.

Figure 9 shows Daily MT and FC output powers curves which are obtained by the proposed method of energy management for the MG. in the figure, the output power is restricted and controlled by electricity trading in Figure 10.

Figure 11 gives values of the cost for the optimized objective function. The curve is roughly consistent with the curve of the load demand. It demonstrates that the proposed algorithm is successfully controlled for the energy management of the distributed generations in MG system.

\section{Conclusion}

In the paper a research of multi-agent technology in MG system was introduced. The agent distributed control structure and implemented coordination of each agents are presented. Then, a bidding and optimal model based on MAS is presented aims to minimize MG's Optimal management while constraining it to meet the load demands are given. In addition, Central Force Optimization (CFO) is new optimization metaheuristic based on gravitational kinematics and a deterministic nature that has been proposed. In this paper, load derivation algorithm has been proposed for short-time load forecasting. The last, simulation results have shown that following load changes the proposed method can guarantee minimum operating cost by real-time electricity trading. 


\section{Acknowledgements}

This research is supported by National Natural Science Foundation of China 51177142 and Hebei province natural science foundation of China F2012203063.

\section{References}

[1] C.A. Hernandez-Aramburo, T.C. Green and N. Mugniot, "Fuel Consumption Minimization of a MG", IEEE Transactions on Industry Applications, vol. 41, pp. 673-681, May/June. 2005.

[2] E. Barklund, N. Pogaku, M. Prodanovic, C. Hernandez-Aramburo and T.C.Green, "Energy Management System with Stability Constraints for Stand-alone Autonomous MicroGrid", in Proc. 2007 IEEE Electrical \& Electronic Engineering Conf. pp. 1 - 6.

[3] Zhangjian and Aiqian, "Application of multi-agent system in a microgrid.automation of electric power systems", 2008, 32(24): 80-83

[4] B.R. Montano, V. Yoon, K.D.J. Liebowitz, "Agent learning in the multi-agent contracting system [MACS]. Decision Support Systems", 2008, 45(1): 140-149

[5] D. Gilbert, M. Aparicio, B. Atkinson, S. Brady, J. Ciccarino, B. Grosof, P. O'Connor, D. Osisek, S. Pritko, R. Spagna and L.Wilson, "IBM Intelligent Agent Strategy", IBM Corporation, 1995.

[6] Z. Jun, L. Junfeng, W. Jie, H.W. Ngan, "A multi-agent solution to energy management in hybrid renewable energy generation system", Renewable Energy.2011, 36: 1352-1363.

[7] T. Logenthiran, D. Srinivasan and A.M. Khambadkone, "Multi-agent system for energy resource scheduling of integrated microgrids in a distributed system", Electric Power Systems Research. 2011, 81: 138-148.

[8] K.H. van Dam, M. Houwing, Z. Lukszo and Ivo Bouwmans, "Agent-based control of distributed electricity generation with micro combined heat and power-Cross-sectoral learning for process and infrastructure engineers", Computers and Chemical Engineering 2008, 32: 205-217.

[9] A. Qian, W. Jun2hong, Z. Jian, "Strategies for Optimal Use of Clean Distributed Energy in Smart Grid", High Voltage Engineering. 2009, 35(11):2813-2819.

[10] A. Qian and Z. Jian, "Optimization Bidding Strategies of Microgrids Based on Multi-Agent System", Power System Technology. 2010, 34(2):46-51.

[11] C. Honggang and C. Pei, "Auction Algorithm Used forMicrogrid MAS Dispatching”, Smart Grid. 2014, 2(1):73-78.

[12] Z. Xiao-lian and Y. Wei, "Research on Reactive Power Optimization Control of Electric Power System Based on Multi-Agent System", Power System Technology. 2008, 32(2):146-149.

[13] C. Peng, Z. Hui, "Research on trading model of micro- grid under market conditions", Power DSM.2011, 13(4):23-29.

[14] L. Shi, Y. Luo, G.Y. Tu, "Bidding strategy of microgrid with consideration of uncertainty for participating in power market", Electrical Power and Energy Systems. 2014,59:1-13.

[15] A.G. Tsikalakis and N.D. Hatziargyriou, "Operation of microgrids with demand side bidding and continuity of supply for critical loads", Euro. Trans. Electr. Power. 2011, 21:1238-1254.

[16] Z. Dong, L. Shuhui, Z. Peng and Z. Chuanzhi, "Optimal Microgrid Control and Power-Flow Study With Different Bidding Policies by Using PowerWorld Simulator", IEEE Transactions on sustainable energy 2014, 5(1):282-292.

[17] W. Lianghong, W. Yaonan, Z. Shaowu and Y. Xiaofang, "Differential Evolution for Nonlinear Constrained Optimization Using Non-stationary Multi-stage Assignment Penalty Function”, system engineering theory \& practice, 3:128-133, 2007.

[18] Z. Bo, G. Chuangxin and C. Yijia, "Optimal Power Flow Using Particle Swarm Optimization and NonStationary Multi-Stage Assignment Penalty Function", Transactions of China Electrotechnical Society, 19(5):47-54, 2004.

[19] C. Yongqiang, W. Bende, and L. Jin, "Water Quality Assessment Model Based on Dualistic Factor Contrast for Indexes Weight Calculation and Its Application", International Journal Hydroelectric Energy, 20(3):19-21, 2002.

[20] R.C. Green, L. Wang and M. Alam, "Training neural networks using Central Force Optimization and Particle Swarm Optimization: Insights and comparisons”, Expert Systems with Applications, 39:555-563, 2012.

[21] Y. Linlin, Q. Weiyi, and Z. Qi, "Central Force Optimization. Journal of Bohai University( Natural Science Edition)", 32(3):203-206, 2011. 


\section{Authors}

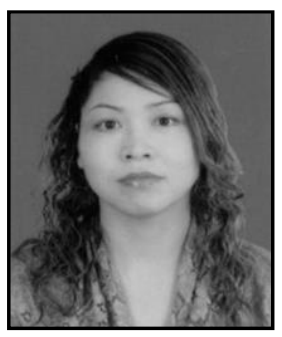

Chun-Xia Dou received the B.S. degree, the M.S. degree, and the Ph.D. degree from the Yanshan University, Qinhuangdao, China. She is currently a professor at the Institute of Electrical Engineering, Yanshan University.

Her research interests include control for smart grid, control for Microgrid, and stability of wide-area power systems.

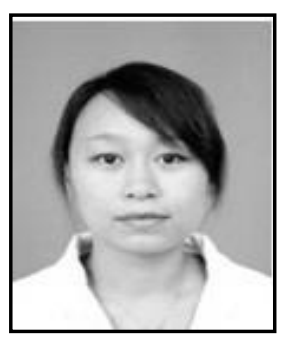

Xingbei Jia received the B.S. degree from the Yanshan University, Qinhuangdao, China, in 2009. She is currently pursuing Dr. in the Institute of Electrical Engineering, Yanshan University, Qinhuangdao, China.

Her research interests include optimal management and control of energy for a microgrid. 